\title{
Anti-diabetic and hypolipidaemic properties of ginger (Zingiber officinale) in streptozotocin-induced diabetic rats
}

\author{
Zainab M. Al-Amin, Martha Thomson, Khaled K. Al-Qattan, Riitta Peltonen-Shalaby and Muslim Ali* \\ Department of Biological Sciences, Faculty of Science, Kuwait University, PO Box 5969, 13060-Safat, Kuwait \\ (Received 29 October 2005 - Revised 12 April 2006 - Accepted 24 April 2006)
}

\begin{abstract}
In the present study, the hypoglycaemic potentials of ginger (Zingiber officinale) were studied in rats. An aqueous extract of raw ginger was administered daily $(500 \mathrm{mg} / \mathrm{kg}$, intraperitoneally) for a period of 7 weeks to streptozotocin (STZ)-induced diabetic rats. Fasting blood serum was analysed for blood glucose, cholesterol and triacylglycerol levels. The STZ-injected rats exhibited hyperglycaemia accompanied with weight loss, indicating their diabetic condition. At a dose of $500 \mathrm{mg} / \mathrm{kg}$, raw ginger was significantly effective in lowering serum glucose, cholesterol and triacylglycerol levels in the ginger-treated diabetic rats compared with the control diabetic rats. The ginger treatment also resulted in a significant reduction in urine protein levels. In addition, the ginger-treated diabetic rats sustained their initial weights during the treatment period. Moreover, ginger decreased both water intake and urine output in the STZ-induced diabetic rats. The present results indicate that raw ginger possesses hypoglycaemic, hypocholesterolaemic and hypolipidaemic potential. Additionally, raw ginger is effective in reversing the diabetic proteinuria observed in the diabetic rats. Thus, ginger may be of great value in managing the effects of diabetic complications in human subjects.
\end{abstract}

Anti-diabetic properties: Diabetes: Ginger: Hypoglycaemic properties: Hypolipidaemic properties: Proteinuria

Before the discovery of insulin in the 1920s and the development of oral hypoglycaemic agents, diabetes mellitus was treated mainly by a combination of fasting, diet control and plant therapeutics (Bailey \& Flatt, 1990). The efficacy of plants in diabetes required confirmation and, therefore, the WHO (World Health Organization, 1980) recommended assessment of traditional plant treatments for diabetes mellitus. Currently, several hundred plants have been reported to have beneficial effects in the treatment of diabetes (Bailey \& Day, 1989; Swanston-Flatt et al. 1991; Gray \& Flatt, 1997, 1999; Hill \& Peters, 2002; Kar et al. 2003; Srinvasan, 2005).

Ginger (Zingiber officinale) is a perennial plant with narrow, bright green, grass-like leaves and yellowish green flowers with purple markings. Ginger is cultivated in the tropics for its edible rhizome at approximately 10 months of age, with the root stocks serving a variety of purposes, including culinary and medicinal (Grant, 2000; Ursell, 2000; Portnoi et al. 2003). The efficacy of ginger is purported to be a result of its aromatic, carminative and absorbent properties (Govindarajan, 1982a,b).

Ginger is a widely used spice and functional food. For centuries ginger has been an important ingredient in Chinese, Ayurvedic and Tibb-Unani herbal medicine. The medicinal properties attributed to ginger include anti-arthritic (Srivastava \& Mustafa, 1989, 1992; Bliddal et al. 2000), anti-migraine (Mustafa \& Srivastava, 1990; Cady et al. 2005), anti-thrombotic (Bordia et al. 1997; Thomson et al.
2002), anti-inflammatory (Thomson et al. 2002, Penna et al. 2003), hypolipidaemic (Bordia et al. 1997; Thomson et al. 2002; Bhandari et al. 2005), hypocholesterolaemic (Furhman et al. 2000; Bhandari et al. 2005) and anti-nausea properties (Ernst \& Pittler, 2000; Portnoi et al. 2003).

Ginger is known to contain a number of potentially bioactive substances, mainly gingerols and their related dehydration products, the shogaols, as well as volatile oils including sesquiterpenes, such as $\beta$-bisabolene and (-)-zingiberene, and monoterpenes, mainly geranial and neral (Chevallier, 1996; Ursell, 2000; McKenna et al. 2002). In particular, gingerols have been shown to inhibit both prostaglandin and leukotriene biosynthesis (Kiuchi et al. 1992) and angiogenesis (Kim et al. 2005). In addition, several ginger components exhibit serotonin receptor-blocking activity (Huang et al. 1991; Abdel-Aziz et al. 2005).

A few isolated studies about the hypoglycaemic properties of ginger in animals have reported variable results. Sharma \& Shukla (1977) reported a small but significant blood glucose-lowering effect of ginger juice in diabetic and non-diabetic animals. Akhani et al. (2004) also observed that ginger juice exhibits hypoglycaemic activity in both normal and streptozotocin (STZ)-induced diabetic rats. Mascolo et al. (1989) reported a significant hypoglycaemic activity in normal rabbits at different times after a variety of administration schedules and doses. Weidner \& Sigwart (2000) reported that an ethanolic extract of ginger had no effect on blood glucose levels in normal rats. In addition, Singhal \& 
Joshi (1983) reported an elevation of blood sugar in normal rats given a dietary dose of $30 \%$ ginger powder. The variability of the results in these studies may be due to the use of different ginger preparations.

The aim of the present study was to investigate the efficacy of an aqueous extract of raw ginger in controlling serum sugar, cholesterol and triacylglycerol levels in STZ-induced diabetic rats treated daily intraperitoneally (IP) for a period of 7 weeks. Since there have been variable reports about the use of different preparations of ginger, aqueous extracts of raw ginger were used in the present study. The mode of administration was chosen to be IP since we have previously reported similar effects with IP and per-oral administration of ginger in normal rats (Thomson et al. 2002) and IP administration was judged to be less stressful for the animals. In addition, the chosen dosage of $500 \mathrm{mg}$ raw ginger extract $/ \mathrm{kg}$ body weight was previously found to be effective and non-toxic in rats while a dosage of $50 \mathrm{mg} / \mathrm{kg}$ gave variable results (Thomson et al. 2002; Alnaqeeb et al. 2003).

\section{Materials and methods}

\section{Extract preparation}

Aqueous ginger extract was prepared from locally available ginger roots. The ginger roots were peeled on crushed ice, and $50 \mathrm{~g}$ ginger were cut into small pieces and homogenised in $75 \mathrm{ml}$ cold, sterile $0.9 \% \mathrm{NaCl}$ in the presence of some crushed ice. The homogenisation was carried out in a blender at high speed using $2 \mathrm{~min}$ bursts for a total of $12 \mathrm{~min}$. The homogenised mixture was filtered three times through cheesecloth (very little material was retained on the cheesecloth). The filtrate was centrifuged at 2000 relative centrifugal force for $10 \mathrm{~min}$ and the clear supernatant fraction was made up to $100 \mathrm{ml}$ with normal saline. The concentration of this ginger preparation was considered to be $500 \mathrm{mg} / \mathrm{ml}$ on the basis of the weight of the starting material $(50 \mathrm{~g} / 100 \mathrm{ml})$. The aqueous extract of ginger root was stored in small samples at $-20^{\circ} \mathrm{C}$ until use. The stability of the preparation during storage has been previously established in platelet aggregation studies (M.Ali, unpublished results).

\section{Treatment of diabetic rats}

Male Sprague-Dawley rats weighing 250-280 g (parents purchased from B and K Universal Co., Hull, UK) and maintained on a normal diet and filtered tap water ad libitum were used in the experiment. For baseline data, blood was drawn from all animals by cardiac puncture under ether anaesthesia and allowed to clot. Immediately, the clotted blood was centrifuged at $3500 \mathrm{rpm}$ for $30 \mathrm{~min}$. The serum was separated and stored at $-80^{\circ} \mathrm{C}$ for later analysis.

The animals were randomly divided into a normal group (eight rats) and an STZ-treated group (initially forty rats). The STZ-treated rats were injected with $60 \mathrm{mg}$ steptozotocin/ $\mathrm{kg}$ body weight IP in a volume of $0.5 \mathrm{ml}$ saline according to the method of Axler (1982). After a period of $3 \mathrm{~d}$, blood was drawn from the STZ-treated animals and serum was prepared and stored for later analysis as described earlier. Serum glucose levels were determined immediately and the STZ-treated rats determined to be diabetic due to a high serum glucose level $(>3500 \mathrm{mg} / \mathrm{l})$ were randomly divided into two groups containing eight animals each: group 1, the control diabetic group, was injected IP daily with saline for the treatment period; group 2, the ginger-treated group, was injected IP daily with $500 \mathrm{mg}$ ginger extract/kg body weight. After periods of 2, 5 and 7 weeks, blood was drawn from the rats by cardiac puncture, and serum was prepared and stored for later analysis as described earlier.

Rats were weighed before the start of the experiment and then weekly during the experimental period. Animals were monitored for general health during the treatment period. Water intake over $24 \mathrm{~h}$ and $24 \mathrm{~h}$ urine output were measured daily in each treatment group before STZ administration and at 2, 5 and 7 weeks by housing the animals in metabolism cages and collecting the urine. Urine samples were stored at $-80^{\circ} \mathrm{C}$ for protein determination.

At the end of the experiment, the rats were killed under sodium pentobarbitone anaesthesia according to the guidelines for euthanasia in the Guide for the Care and Use of Laboratory Animals (National Research Council, 1996).

\section{Assays}

Serum glucose, cholesterol and triacylglycerol levels were determined spectrophotometrically using kits supplied by CARO Co. (Hamburg, Germany). Urine protein was determined by the Coomassie Blue dye-binding method of Bradford (1976).

\section{Statistical analysis}

The data are expressed as mean values with their standard errors. Readings of the three different groups were compared using one-way ANOVA analysis and readings between two different groups were compared using the independent sample test. Statistical analysis was performed using SPSS (version 13; SPSS Inc., Chicago, IL, USA). A level for $P<0.05$ was considered to be significant.

\section{Results}

The effect of ginger on serum glucose, cholesterol and triacylglycerol levels was determined by comparison of normal, control diabetic, and ginger-treated diabetic rats. Serum glucose, cholesterol and triacylglycerols were measured before and during ginger treatment as shown in Figs. 1 to 3 .

It is clear from the data in Fig. 1 that the serum glucose levels of the control diabetic animals continued to increase during the 7 weeks of the experiment compared with the post-STZ injection level. In contrast, the ginger-treated diabetic rats exhibited significantly reduced glucose levels during the treatment period when compared with the control diabetic rats. After 7 weeks of treatment with ginger extract, the serum glucose levels of the ginger-treated diabetic rats were significantly reduced $(52 \%$ reduction; $P<0.05)$ in comparison with the control diabetic rats.

Fig. 2 shows that 1 week after STZ injection, the serum cholesterol level of control diabetic rats increased significantly above the normal level. After treatment, the serum cholesterol levels of ginger-treated diabetic rats significantly decreased (44\% reduction) in comparison with control diabetic rats. 


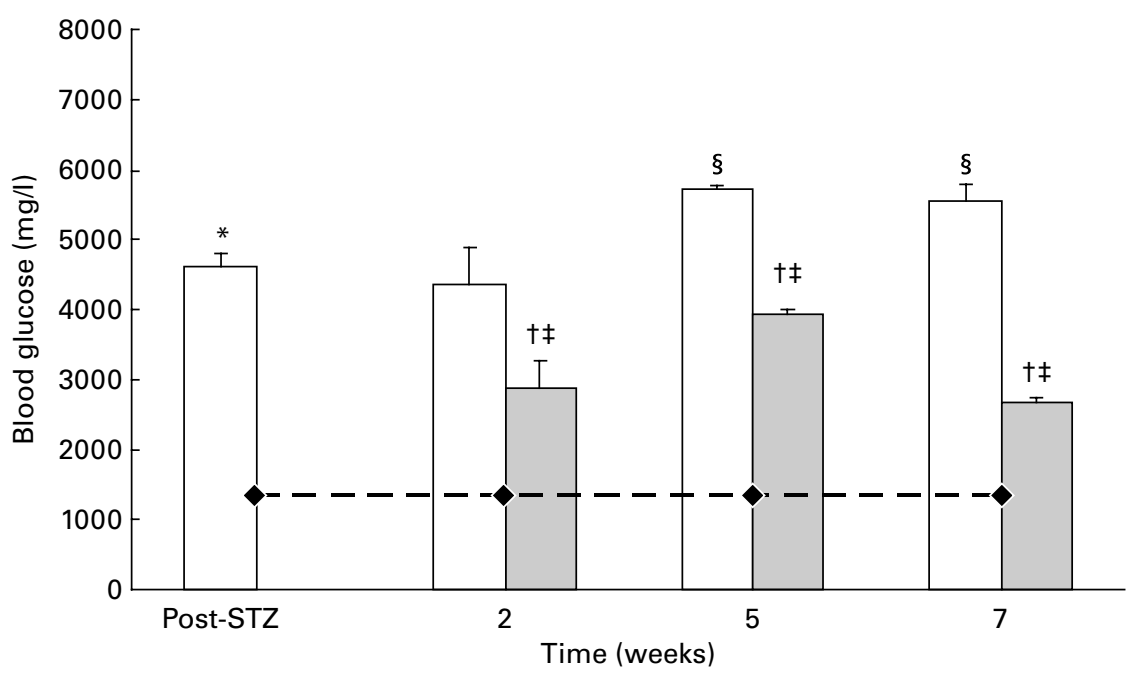

Fig. 1. Serum glucose levels in streptozotocin (STZ)-induced diabetic rats treated with aqueous extract of ginger. Glucose levels were measured in serum of normal rats (averaged over the experimental period; $-\checkmark-$ ), STZ-induced diabetic rats (control diabetic rats; $\square$ ) and ginger-treated STZ-induced diabetic rats $(\square$ ). Analysis was done post-STZ injection, and after 2, 5 and 7 weeks of treatment. Values are means, with their standard errors represented by vertical bars. ${ }^{*}$ Mean value was significantly increased compared with saline control $(P<0.05)$. † Mean value was significantly decreased compared with control diabetic rats $(P<0.05)$. ¥ Mean value was significantly decreased compared with ginger-treated diabetic rats after STZ injection $(P<0.05)$. $\S$ Mean value was significantly increased compared with post-STZ injection $(P<0.05)$.

The blood cholesterol reduction elicited by raw ginger was sustained throughout the course of treatment. Similarly, Fig. 3 shows a significant reduction in serum triacylglycerol levels during the 7 weeks of treatment ( $41 \%$ reduction). In contrast, the serum cholesterol and triacylglycerol levels remained elevated in the control diabetic group throughout the experimental period.

The normal rats gained weight significantly during the experimental period, while in comparison the control diabetic animals showed a significant decrease in body weight compared with the normal rats (Fig. 4). In contrast, the ginger-treated diabetic rats exhibited a levelling of their weights during the treatment period; that is, these animals initially lost weight but their weights stabilised after 2 weeks of ginger treatment and remained approximately the same (about $90 \%$ of the starting weight) during the last 5 weeks of treatment. In contrast, the control diabetic rats decreased their weights significantly in comparison with both the normal rats and the ginger-treated diabetic rats at week 7 of the experimental period.

Urine protein levels of ginger-treated rats were significantly reduced compared with control diabetic animals (Fig. 5). At 1 week after STZ injection, there was an increase in the urine protein level compared with the normal level (almost doubled; $P<0.05)$ and the urine protein levels remained elevated in the control diabetic rats during the 7 weeks of the present study. However, during the ginger treatment, the urine protein level decreased significantly in comparison with the control diabetic level, such that after 2, 5 and 7 weeks of ginger treatment, a remarkable decrease $(39,60$ and $60 \%$ decrease, respectively) in urine protein level was observed $(P<0 \cdot 05)$. It is noteworthy that after 5 and 7 weeks of ginger treatment, the urine protein levels of the ginger-treated diabetic rats were approximately equal to the level in the normal rats.

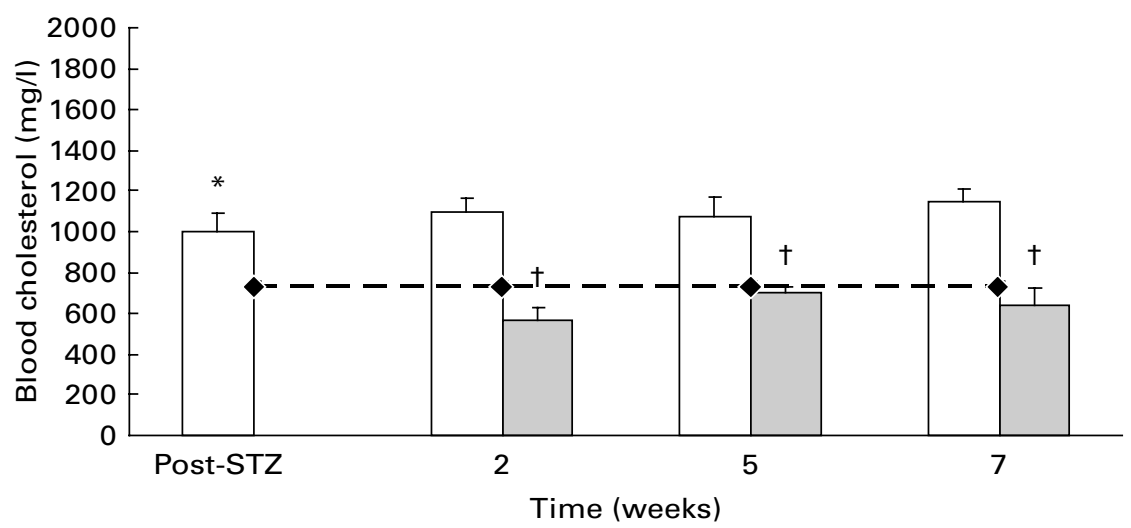

Fig. 2. Serum cholesterol levels in streptozotocin (STZ)-induced diabetic rats treated with aqueous extracts of ginger. Cholesterol levels were measured in serum of normal rats (averaged over the experimental period; - - ), STZ-induced diabetic rats (control diabetic rats; $\square$ ) and ginger-treated STZ-induced diabetic rats ( $\square$ ). Analysis was done post-STZ injection, and after 2, 5 and 7 weeks of treatment. Values are means, with their standard errors represented by vertical bars. ${ }^{*}$ Mean value was significantly increased compared with normal $(P<0.05)$. † Mean value was significantly decreased compared with diabetic control rats $(P<0.05)$. 


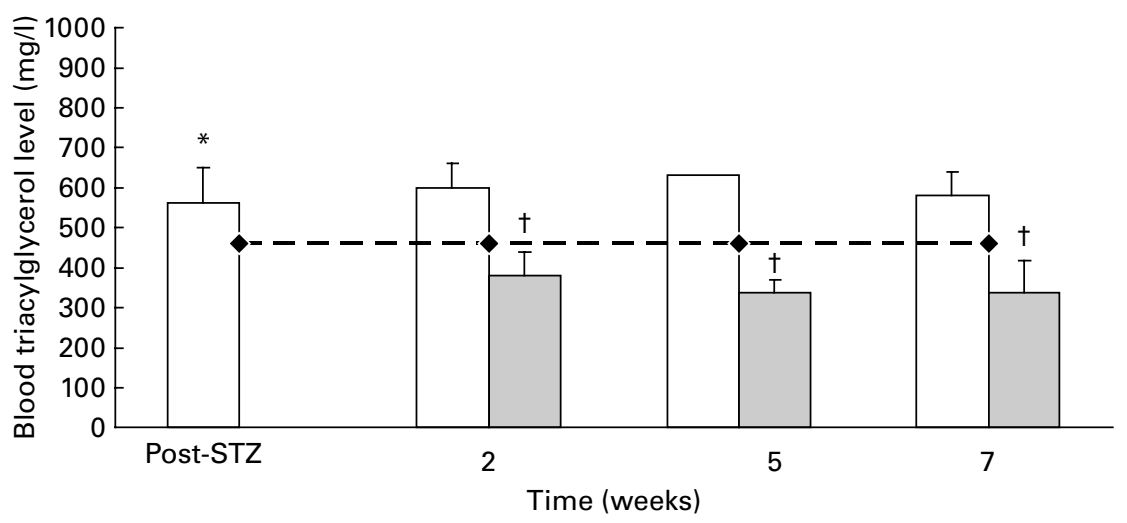

Fig. 3. Serum triacylglycerol levels in streptozotocin (STZ)-induced diabetic rats treated with aqueous extracts of ginger. Triacylglycerol levels were measured in serum of normal rats (averaged over the experimental period; - - -), STZ-induced diabetic rats (control diabetic rats; $\square$ ) and ginger-treated STZ-induced diabetic rats $(\square)$. Analysis was done post-STZ injection, and after 2, 5 and 7 weeks of treatment. Values are means, with their standard errors represented by vertical bars. * Mean value was significantly increased compared with saline control $(P<0.05)$. $†$ Mean value was significantly decreased compared with diabetic control rats $(P<0.05)$.

In the analysis of the data on urine output, it was found that the effect of ginger on diabetic rats was to significantly decrease their urine output during the treatment period (Fig. 6). In addition, the ginger-treated diabetic animals significantly decreased their water intake compared with the control diabetic rats, such that at weeks 5 and 7 of ginger treatment, water intake was significantly decreased compared with the post-STZ level (Fig. 7). However, both the urine output and water intake levels remained several-fold higher than normal levels in the ginger-treated diabetic rats.

\section{Discussion}

Diabetes mellitus is a chronic disorder caused by partial or complete insulin deficiency which produces inadequate

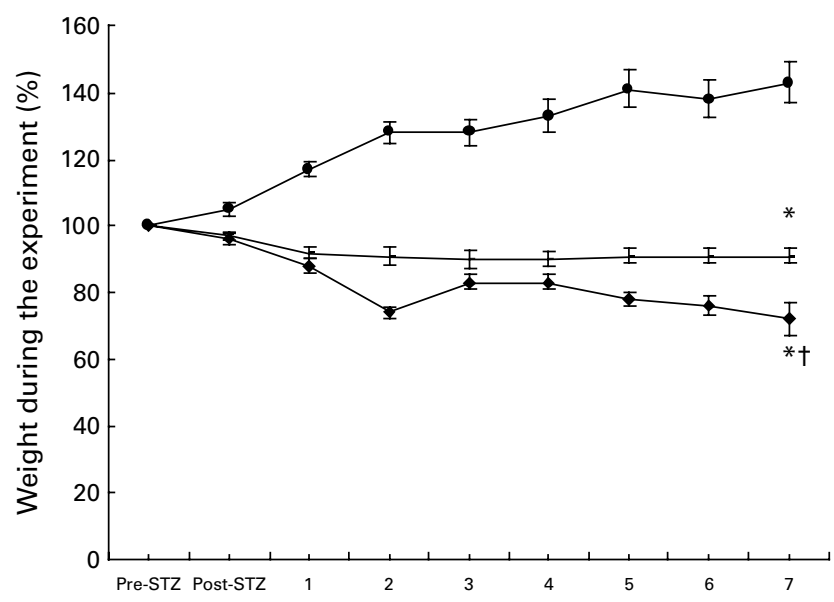

Fig. 4. Weights of normal and streptozotocin (STZ)-induced diabetic rats over

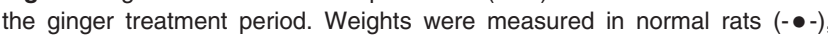
STZ-induced diabetic rats (control diabetic rats; - $\bullet$-) and ginger-treated STZinduced diabetic rats $(-)$. The animals were weighed before STZ injection (pre-STZ), 1 week after STZ injection (post-STZ), and then weekly during the treatment period of 7 weeks. Weights are plotted as percentiles with the starting weights all standardised to $100 \%$. Values are means, with their standard errors represented by vertical bars. * Mean value was significantly decreased compared with normal at week $7(P<0.05)$. † Mean value was significantly different between control diabetic and ginger-treated diabetic rats $(P<0.05)$. blood glucose control and leads to acute and chronic complications (White \& Baxter, 1994). Overt symptoms of diabetes mellitus include hyperglycaemia, increased water intake and polyuria (White \& Baxter, 1994). Chronic complications can involve the kidneys (nephropathy), eyes, nervous system and cardiovascular system (Koda-Kimble \& Carlisle, 1995). In fact, diabetes is the number one cause of chronic kidney disease in the USA (Chua \& Bakris, 2004)

Diabetic nephropathy occurs when proteins deposit in the glomerulus (Clark \& Lee, 1995). Thickening of the glomerular capillary basement membrane narrows the lumen of the capillaries impeding blood flow and subsequently reducing the filtering surface of the glomerulus (Koda-Kimble \& Carlisle, 1995). The principal indicator of diabetic nephropathy is proteinuria (Nathan, 1993).

Therefore, the present study was undertaken to evaluate the anti-diabetic properties of an aqueous extract of ginger in STZ-induced diabetic rats. STZ diabetic rats showed significant increase in serum glucose, cholesterol and triacylglycerol levels. The present results clearly show that an aqueous extract of raw ginger effectively lowers serum glucose, cholesterol and triacylglycerol levels in diabetic rats. However, it should be noted that serum glucose levels in ginger-treated diabetic rats did not reach normal levels at the dosage used in the present study. A similar result was reported by Akhani et al. (2004) in their study on the effects of ginger juice in STZinduced diabetic rats.

In addition, the present results also demonstrate that the raw ginger extract completely eliminated the proteinura that is caused by diabetic nephropathy (Fig. 5). The decrease in protein in the urine of raw ginger-treated diabetic rats was accompanied by a decrease in the water intake and urine output by the diabetic rats. Thus, the present results suggest that treatment with ginger helped to alleviate the nephropathy resulting from STZ-induction of diabetes. However, these water intake results are in contrast to the study of Akhani et al. (2004) that reported no change in diabetic polydypsia in STZ-induced diabetic rats treated with ginger.

Previous studies of the hypoglycaemic properties of ginger in human subjects and animals have produced variable results. The administration of an ethanolic extract of ginger (100 or 


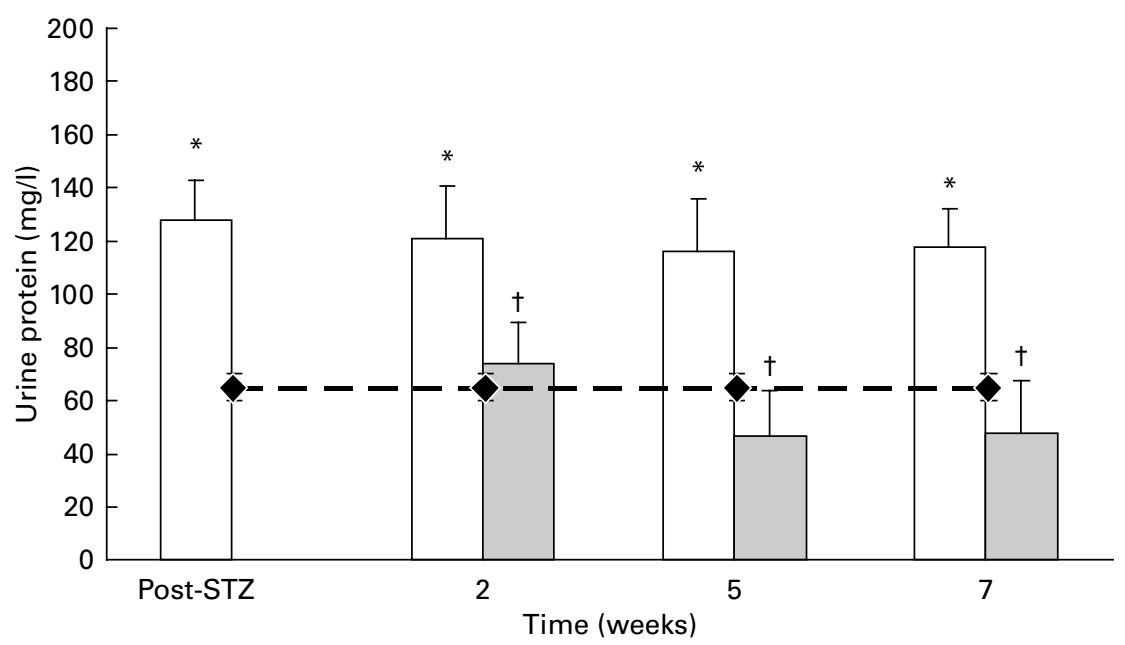

Fig. 5. Urine protein levels in streptozotocin (STZ)-induced diabetic rats treated with aqueous extracts of ginger. Protein levels were measured in urine of normal rats (averaged over the experimental period; - -), STZ-induced diabetic rats (control diabetic rats; $\square$ ) and ginger-treated STZ-induced diabetic rats ( $\square$ ). Analysis was done post-STZ injection, and after 2, 5 and 7 weeks of treatment. Values are means, with their standard errors represented by vertical bars. ${ }^{*}$ Mean value was significantly increased compared with normal $(P<0.005)$. † Mean value was significantly decreased compared with control diabetic rats $(P<0.05)$.

$300 \mathrm{mg} / \mathrm{kg}$ ) to normal rabbits showed potential hypoglycaemic activity $(51 \%$ decrease in serum glucose) $2 \mathrm{~h}$ after administration (Mascolo et al. 1989). In contrast, in another study, non-diabetic patients with coronary artery disease showed no decrease in their blood lipid or sugar levels when treated with a daily dose of $4 \mathrm{~g}$ powdered ginger for a period of 3 months (Bordia et al. 1997). Akhani et al. (2004) have reported that ginger juice exhibits hypoglycaemic activity in both normal and STZ-induced diabetic rats. Clearly, the results in the present study confirm the observations of Akhani et al. (2004) pertaining to glucose control. No previous studies have reported changes in kidney function as a result of ginger administration.

The major pungent component of ginger is gingerol, a mixture of homologues with 10,12 and 14 carbons in the side chain designated (6)- (8)- and (10)-gingerols (Mustafa et al. 1994). Gingerols can be converted to shogoals and zingerone by dehydration and retro-aldol reaction, respectively. Zingerone and shogaol are found in small amounts in fresh ginger (Govindarajan, 1982a,b). These ginger components have been shown to have a variety of pharmacological effects, including anti-inflammatory, anti-emetic, cardiotonic and gastroprotective properties (Mustafa et al. 1994).

Several reports have detailed serotonin receptor-blocking activity of ginger and its components (Huang et al. 1991; Akhani et al. 2004; Abdel-Aziz et al. 2005). Since 5-hydroxytryptamine has been reported to induce hyperglycaemia in rats (Yamada et al. 1999), Akhani et al. (2004) investigated the effect of ginger juice on serotonin-induced hyperglycaemia and hypoinsulinaemia in normoglycaemic rats and reported that ginger juice inhibited this inductive effect. In addition, Akhani et al. (2004) reported that ginger juice partially alleviated the hypoinsulinaemia observed in STZinduced diabetic rats.

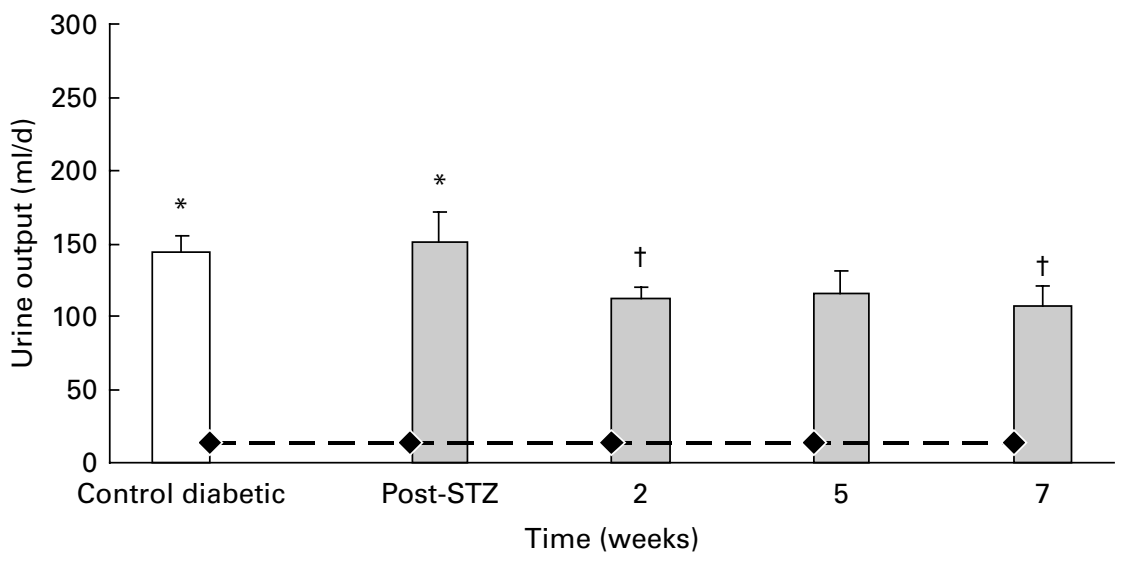

Fig. 6. Urine output in streptozotocin (STZ)-induced diabetic rats treated with aqueous extracts of ginger. Urine output was measured in rats post-STZ injection, and after 2, 5 and 7 weeks of ginger treatment of STZ-induced diabetic rats $(\square)$. Normal urine output levels were averaged over the experimental period $(-\bullet-)$. Urine output levels in control diabetic rats were averaged over the experimental period $(\square)$. Values are means, with their standard errors represented by vertical bars. * Mean value was significantly increased compared with normal $(P<0.05)$. $†$ Mean value was significantly decreased compared with control diabetic rats $(P<0.05)$. 


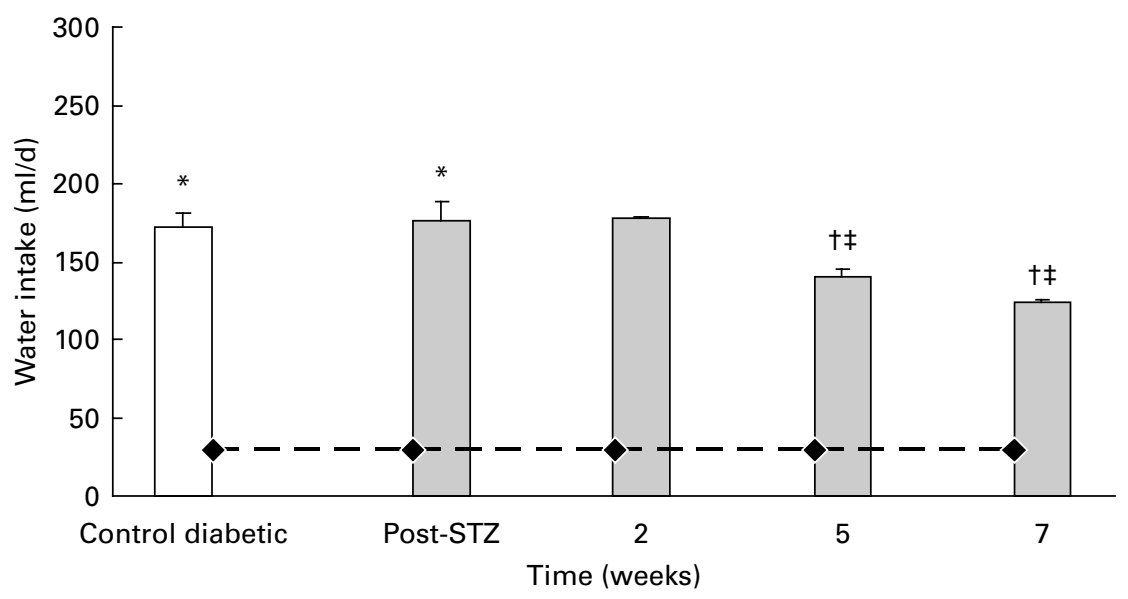

Fig. 7. Water intake in streptozotocin (STZ)-induced diabetic rats treated with aqueous extracts of ginger. Water intake was measured in rats post-STZ injection and after 2, 5 and 7 weeks of ginger treatment of STZ-induced diabetic rats $(\square)$. Normal water intake levels were averaged over the experimental period $(-\downarrow-)$. Water intake levels in control diabetic rats were averaged over the experimental period $(\square)$. Values are means, with their standard errors represented by vertical bars. * Mean value was significantly increased compared with normal $(P<0.05)$. $\dagger$ Mean value was significantly decreased compared with control diabetic rats $(P<0.05)$. $\ddagger$ Mean value was significantly decreased compared with post-STZ level $(P<0.05)$.

There have been no reports on the effects of any of the known ginger components on hyperglycaemia. Therefore, further work should be undertaken to evaluate the potential anti-diabetic properties of pure ginger components and possibly determine the mechanism of these anti-diabetic effects of ginger, in particular the renal effects.

In the present study, using a diabetic rat model, we have shown that an aqueous extract of raw ginger has potential hypoglycaemic properties. This hypoglycaemic action of ginger may be due to effects involving serotonin receptors, an increase in pancreatic secretion of insulin from $\beta$ cells or release of bound insulin. Further work is needed to investigate how ginger lowers glucose levels in diabetic rats. In addition, the results also demonstrate that raw ginger can potentially reverse the nephropathy in STZ-induced diabetic rats. Since urinary albumin levels are a selective marker of glomerular injury and elevated levels of urinary albumin are a harbinger of progressive nephropathy (Viberti et al. 1982), future studies should focus on the effects of ginger administration on urinary albumin levels. It should be noted that we have previously reported that the doses of ginger used in the present study are not toxic in rats (Alnaqeeb et al. 2003). Therefore, it can be concluded from these studies that raw ginger has significant potential in the treatment of diabetes. Further study is underway to investigate the active component(s) of ginger responsible for the observed beneficial effects in the diabetic condition.

\section{Acknowledgements}

The present study was supported by Kuwait University grant number SB01/99 and the College of Graduate Studies, Kuwait University, for which the authors are grateful.

\section{References}

Abdel-Aziz H, Nahrstedt A, Peterelt F, Windeck T, Ploch M \& Verspohl EJ (2005) 5-HT3 receptor blocking activity of arhyalkanes isolated from the rhizome of Zingiber officinale. Planta Med 71, 609-616.
Akhani SP, Vishwakarma SL \& Goyal RK (2004) Anti-diabetic activity of Zingiber officinale in streptozotocin-induced type I diabetic rats. J Pharm Pharmacol 56, 101-105.

Alnaqeeb MA, Thomson M, Al-Qattan KK, Kamel F, Mustafa T \& Ali M (2003) Biochemical and histopathological toxicity of ginger (Zingiber officinale) in rats. Kuwait J Sci Eng 30, 35-48.

Axler DA (1982) Stability of the diabetogenic activity of streptozotocin. IRCS Med Sci 10, 157-165.

Bailey CJ \& Day C (1989) Traditional plant medicines as treatments for diabetes. Diabetes Care 12, 553-564.

Bailey CJ \& Flatt PR (1990) New Antidiabetic Drugs. London: Smith-Gordon.

Bhandari U, Kanojia R \& Pillai KK (2005) Effect of ethanolic extract of Zingiber officinale on dyslipidaemia in diabetic rats. J Ethnopharmacol 97, 227-230.

Bliddal H, Rosetzsky A, Schlichting P, Weidner MS, Andersen LA, Ibfelt H-H, Christensen K, Jensen ON \& Barslev J (2000) A randomized, placebo-controlled, cross-over study of ginger extracts and ibuprofen in osteoarthritis. Osteoarthritis Cartilage 8, 9-12.

Bordia A, Verma SK \& Srivastava KC (1997) Effect of ginger (Zingiber officinale Rosc.) and fenugreek (Tringonella foenumgraecum L.) on blood lipids, blood sugar and platelet aggregation in patients with coronary artery disease. Prostagl Leukotr Essen Fatty Acids 56, 379-384.

Bradford M (1976) A rapid and sensitive method for the quantification of microgram quantities of protein utilizing the principle of protein-dye binding. Anal Biochem 72, 248-254.

Cady RK, Schreiber CP, Beach ME \& Hart CC (2005) Gelstat Migraine ${ }^{\circledR}$ (sublingually administered feverfew and ginger compound) for acute treatment of migraine when administered during the mild pain phase. Med Sci Monit 11, 165-169.

Chevallier A (1996) The Encyclopedia of Medicinal Plants. London: Dorling Kindersley Ltd..

Chua DY \& Bakris GL (2004) Diabetes and chronic kidney disease: tragedy and challenge. Blood Purif 22, 130-135.

Clark CM \& Lee DA (1995) Drug therapy: prevention and treatment of complications of diabetes mellitus. $N$ Engl J Med 332, $1210-1217$.

Ernst E \& Pittler MH (2000) Efficacy of ginger for nausea and vomiting: a systematic review of randomized clinical trials. Brit J Anaes 84, 367-371.

Fuhrman B, Rosenblat M, Hayek T, Coleman R \& Aviram M (2000) Ginger extract consumption reduces plasma cholesterol, inhibits 
LDL oxidation and attenuates development of atherosclerosis in atherosclerotic, apolipoprotein E-deficient mice. J Nutr 130, $1124-1131$

Govindarajan VS (1982a) Ginger - chemistry, technology, and quality evaluation: part 1. Crit Rev Food Sci Nutr 17, 1-96.

Govindarajan VS (1982b) Ginger - chemistry, technology, and quality evaluation: part 2. Crit Rev Food Sci Nutr 17, 189-258.

Grant KI (2000) Ginger. Am J Heath Syst Pharm 57, 945-947.

Gray AM \& Flatt PR (1997) Nature's own pharmacy: the diabetes perspective. Proc Nutr Soc 56, 507-517.

Gray AM \& Flatt PR (1999) Insulin-releasing and insulin-like activity of the traditional anti-diabetic plant Coriandrum sativum (coriander). Br J Nutr 81, 203-209.

Hill JO \& Peters JC (2002) Biomarkers and functional foods for obesity and diabetes. Br J Nutr 88, Suppl., S213-S218.

Huang QR, Iwanmoto M, Aoki S, Tanaka N, Tajima K, Yamahara J, Takaishi Y, Yoshida M, Tomimatsu T \& Tamai Y (1991) Anti-5hydroxytryptamine3 effect of galanolactone, diterpenoid isolated from ginger. Chem Pharm Bull (Tokyo) 39, 397-399.

Kar A, Choudhary BK \& Bandyopadhyay NG (2003) Comparative evaluation of hypoglycaemic activity of some Indian medicinal plants in alloxan diabetic rats. J Ethnopharmacol 84, 105-108.

Kim E-C, Min J-K, Kim T-Y, Lee S-J, Yang H-O, Han S, Kim Y-M \& Kwon Y-G (2005) [6]-Gingerol, a pungent ingredient of ginger, inhibits angiogenesis in vitro and in vivo. Biochem Biophys Res Comm 335, 300-308.

Kiuchi F, Iwakami S, Shibuya M, Hanaoka F \& Sankawa U (1992) Inhibition of prostaglandin and leukotriene biosynthesis by gingerols and diarylheptanoids. Chem Pharm Bull (Tokyo) 40, 387-391.

Koda-Kimble MA \& Carlisle BA (1995) Diabetes mellitus. In Applied Therapeutics: the Clinical Use of Drugs, 6th ed. pp. 48-1-48-58 [LY Young, MA Koda-Kimble, WA Kradjan and BJ Guglielmo, editors]. Vancouver, BC, Canada: Applied Therapeutics.

McKenna DJ, Jones K, Hughes K \& Humphrey S (2002) Ginger. In Botanical Medicines, the Desk Reference for Major Herbal Supplements, 2nd ed. pp. 411-444. New York: The Haworth Herbal Press.

Mascolo N, Jain R, Jain SC \& Capasso F (1989) Ethnopharmacologic investigation of ginger (Zingiber officinale). J Ethnopharmacol 27, $129-140$.

Mustafa T \& Srivastava KC (1990) Ginger (Zingiber officinale) in migraine headache. J Ethnopharmacol 29, 267-273.

Mustafa T, Srivastava KC \& Jensen KB (1994) Drug development report (9): Pharmacology of ginger, Zingiber officinale. J Drug Dev 6, 25-39.

National Research Council (1996) Veterinary medical care. In Guide for the Care and Use of Laboratory Animals, pp. 56-70. Washington, DC: National Academy Press.
Nathan DM (1993) Long-term complications of diabetes mellitus. $N$ Engl J Med 328, 1676-1685.

Penna SC, Medeiros MV, Aimbire FS, Faria-Neto HC, Sertie JA \& Lopes-Martins RA (2003) Anti-inflammatory effect of the hydralcoholic extract of Zingiber officinale rhizomes on rat paw and skin edema. Phytomed 10, 381-385.

Portnoi G, Chng LA, Karimi-Tabesh L, Koren G, Tan MP \& Einarson A (2003) Prospective comparative study of the safety and effectiveness of ginger for the treatment of nausea and vomiting in pregnancy. Am J Obstet Gynecol 189, 1374-1377.

Sharma M \& Shukla S (1977) Hypoglycaemic effect of ginger. J Res Ind Yoga Homeop 12, 127-130.

Singhal PC \& Joshi LD (1983) Glycaemic and cholesterolemic role of ginger and till. $J$ Sci Res Plants Med 4, 32-34.

Srinvasan K (2005) Plant foods in the management of diabetes mellitus: spices as beneficial antidiabetic food adjuncts. Int $J$ Food Sci Nutr 56, 399-414.

Srivastava KC \& Mustafa T (1989) Ginger (Zingiber officinale) and rheumatic disorders. Med Hyp 29, 25-28.

Srivastava KC \& Mustafa T (1992) Ginger (Zingiber officinale) in rheumatism and musculoskeletal disorders. Med Hyp 39, $342-348$.

Swanston-Flatt SK, Flatt PR, Day C \& Bailey CJ (1991) Traditional dietary adjuncts for the treatment of diabetes mellitus. Proc Nutr Soc 50, 641-651.

Thomson M, Al-Qattan KK, Al-Sawan SM, Alnaqeeb MA, Khan I \& Ali M (2002) The use of ginger (Zingiber officinale Rosc.) as a potential anti-inflammatory and antithrombotic agent. Prostagl Leukotr Essen Fatty Acids 67, 475-478.

Ursell A (2000) The Complete Guide to Healing Foods, pp. 112-114. London: Dorling Kindersley Ltd.

Viberti GC, Hill RD, Jarett RJ, Argyropolous A, Mahmud U \& Kern H (1982) Microalbuminuria as a predictor of clinical nephropathy in insulin dependent diabetes mellitus. Lancet i, 1430.

Weidner M \& Sigwart K (2000) The safety of a ginger extract in the rat. J Ethnopharmacol 73, 513-520.

White DA \& Baxter M (1994) Diabetes mellitus. In Hormones and Metabolic Control, 2nd ed. pp. 79-92 [DA White and M Baxter, editors]. London: Arnold.

World Health Organization (1980) World Health Organization Expert Committee on Diabetes Mellitus, Second Report. Technical Report Series no. 646, pp. 66. Geneva: WHO.

Yamada J, Sugimoto Y \& Inoue K (1999) Selective serotonin reuptake inhibitors fluoxetine and fluvosamine induce hyperglycemia by different mechanisms. Eur J Pharmacol 382, 211-215. 